\title{
Depletion Efficiency of Selected Expired Food Products in the Process of Methane Fermentation
}

\author{
Joanna Kazimierowicz' \\ 1 Faculty of Civil and Environmental Engineering, Białystok University of Technology, ul. Wiejska 45A, \\ 15-351 Białystok, Poland, e-mail: j.kazimierowicz@pb.edu.pl
}

\begin{abstract}
In retail chains, $1 \%$ to $3 \%$ of food production, i.e. thousands of tons every year, is perished or expired. Improper waste management poses a threat for human health and pollutes the environment. This waste may be successfully neutralised in the process of methane fermentation. The conducted research was to determine the depletion efficiency of selected expired food products, depending on the composition of the mix, as well as the manner of conducting fermentation and, therefore, duration time and the process temperature.
\end{abstract}

Keywords: expired food products, neutralising organic waste, mesophilic fermentation, thermophilic fermentation, depletion efficiency

\section{INTRODUCTION}

Many kinds of biomass may be used to produce biogas [Gradziuk 2003; Kazimierowicz and Dzienis 2015, Kościk and Kowalczyk-Juśko 2004] Application of the methane fermentation process allows both to neutralise the expired food products and to obtain biogas, i.e. a source of renewable energy. The up-to-date research has provided only the general information about the possibilities of utilizing and obtaining biogas from this type of organic substrates (Jędrczak 2008, Pawilonis et al. 2006, Sadecka et al. 2013, Szatkowska et al. 2014, Neterowicz et al. 2015).

The by-product of anaerobic process of organic matter decomposition is post-fermentation sludge, rich in nutrients. Although large amounts of this sludge require special utilisation methods, it should not be treated as waste but rather as a valuable source of minerals and energy. It may be used in agriculture or in natural areas, thermally processed or ultimately deposited at landfill sites. Each of the described methods has both advantages and disadvantages, and affects the environment differently. Therefore, methods should be selected depending on the composition of the digestate, characteristic features and geographical location of the area of its designation so that they are safe and cost-effective. In Poland, post-fermentation sludge is usually thermally utilised or used in agriculture. Large part of the sludge is landfilled; however, this method should not be used because it does not bring any benefits. Fertilisation of the energy potential generated in the substance is lost. Application in agriculture, in contrast to landfilling, is very beneficial due to proper fertilisation properties of the post-fermentation sludge. Thermal use enables producing additional energy as well as valuable ash which, owing to the high amount of minerals, may be used as a fertiliser (Puyuelo et al. 2010, Kazimierowicz 2014).

Decomposition of organic matter depends on the temperature of the process. Particular types of bacteria require different temperatures to be active. This is connected with the content of water in the cells. The lower the water content, the higher the thermal resistance of the organisms. While selecting the temperature of the process, it should be adjusted to the bacteria of particular stages of methanogenesis. The majority of bacteria are mesophiles, for which the the optimum for growth is between $25-45^{\circ} \mathrm{C}$. On the other hand, the thermophilic bacteria tolerate temperature even over $55^{\circ} \mathrm{C}$. The installations operating in 
the scope of the mesophilic bacteria activity are the most common. This results from the fact that gas yield in this temperature range is the greatest and good stability of the process is preserved (Jędrczak 2008, Głodek 2010).

However, mesophilic conditions do not allow full hygienization of fermented material. Not until the process is conducted in the thermophilic temperature range, it enables high level of hygienization of fermented substrate. Significant gas yield is obtained but the process of fermentation in this temperature range is more sensitive to distortion (IEO 2013).

\section{MATERIAL AND METHODS}

The material for the research involved the expired food products from big retail chains belonging to the following groups:

- meat products: pork;

- dairy: drinking milk $3.2 \%$, full-fat cottage cheese, natural yoghurt $2 \%$;

- fruit and vegetables: apples, carrots, tomatoes.

Mixes with different percentage of particular substrate groups were prepared and presented in Figure 1. The aim of this technological process was to determine which substrate mix allows to obtain the largest depletion efficiency of the analysed components.

The research was conducted in the laboratories of the Department of Environmental Engineering Systems, Department of Environmental
Protection and Management as well as in Department Chemistry Laboratory of Bialystok University of Technology. Under the laboratory conditions, the substrates were shredded, mixed in proper proportions and then homogenised and hygienized. Afterwards, they were hydrated, a buffer was added (sodium bicarbonate solution $\left(\mathrm{NaHCO}_{3}\right)$ with concentration of $\left.60 \mathrm{~g} / \mathrm{dm}_{3}\right)$ and in such form they were used as input into fermentation chambers.

The experiment was conducted with the use of respirometric sets Oxi-Top Control type by WTW - modular, mercury-free measuring system. The expired food products introduced once into reactors were subjected to the process. Chambers were inoculated with anaerobic sewage sludge. Static test was conducted under anaerobic and thermophilic conditions. Sets were placed for 25 days in a thermostatic cabinet, at $35^{\circ} \mathrm{C}$ and mesophilic fermentation was conducted. The selection criterion for fermentation time was the assumption to obtain total decomposition of organic substances in the tested mixes. In the case of thermophilic fermentation, the procedure was analogical, providing the conditions suitable for this type of fermentation, i.e. proper calculation of the dosed substrate and maintaining temperature on the level of $55^{\circ} \mathrm{C}$ for 15 days. The selection of fermentation time, similarly as in the case of mesophilic fermentation, was determined by the assumption to obtain decomposition of organic substances in the prepared mixes of substrates.

Qualitative analyses of the expired food products mixes and sludge constituting inoculum of

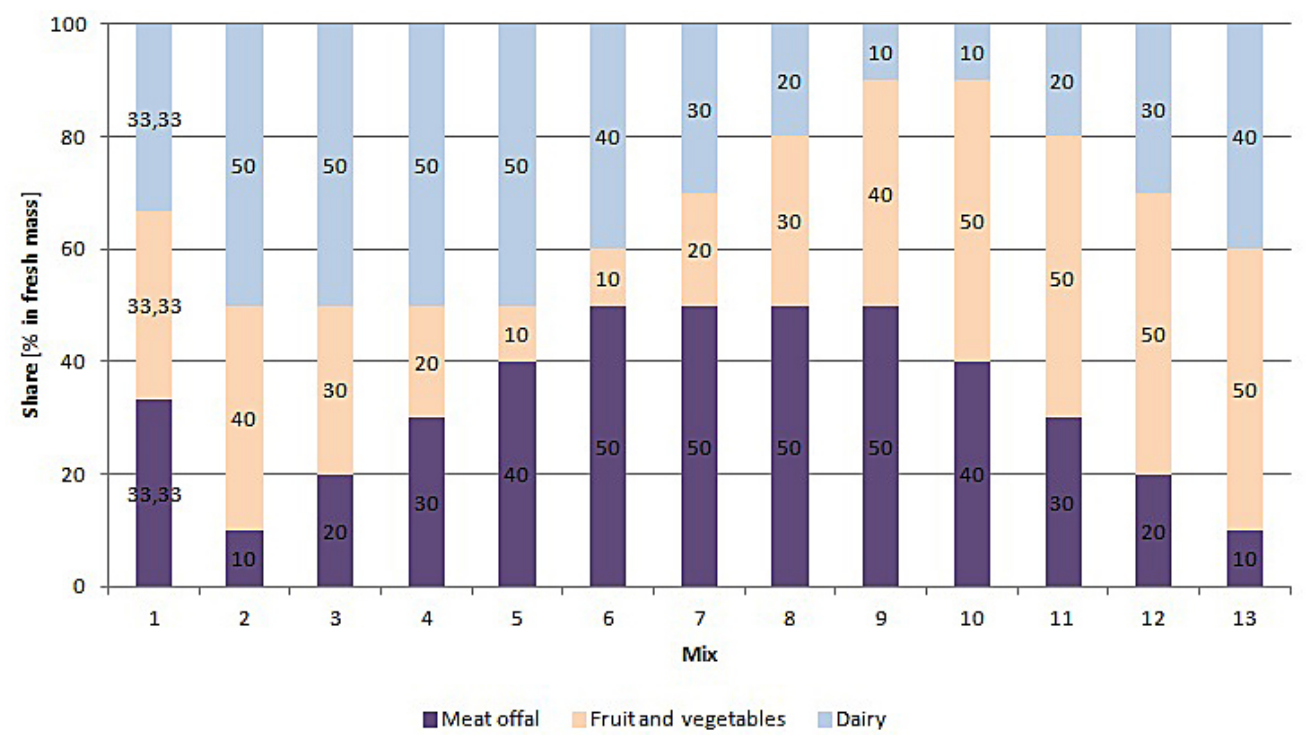

Fig. 1. Proportions of expired food products in substrate mix 
operated fermentation chambers were conducted. The post-fermentation sludge was analysed as well. The scope of analysis conducted in the prepared mixes and fermentation residues is presented in Table 1.

The research was conducted in triplicate. On the basis of obtained results, the overall efficiency of selected components removal was determined, considered in the arrangement: mix before fermentation - post-fermentation sludge. The mesophilic and thermophilic fermentation under static conditions were taken into consideration. The overall efficiency was calculated using the following formula:

$$
\eta=\frac{C o-C}{C o} \cdot 100 \%
$$

where: $\eta$-overall efficiency [\%],

$C_{o}$ - value/concentration of a given parameter before fermentation,

$C$ - value/concentration of a given parameter after fermentation.

\section{RESEARCH RESULTS AND DISCUSSION}

The depletion efficiency in DM and OM depends on the type of conducted fermentation, as well as on the composition of the mixes subjected to the process. The results of the conducted research (Figure 2) indicate that during the mesophilic fermentation, the highest depletion efficiency of the DM and OM was achieved in reactor 8 , with the mix of: $50 \%$ meat, $10 \%$ dairy, $40 \%$ fruit and vegetables. The depletion efficiency amounted to: $81.90 \pm 0.17 \%$ and $87.84 \pm 0.10 \%$, respectively. On the other hand, the lowest depletion efficiency of these parameters was in reactor 13 (10\% meat, $40 \%$ dairy, $50 \%$ fruit and vegetables) $-72.20 \pm 0.02 \%$ and $76.68 \pm 0.09 \%$, respectively. During the thermophilic fermentation, the best depletion effects were also achieved in reactor 8 , i.e. $63.51 \pm 0.17 \%$ of dry matter and $70.56 \pm 0.01 \%$ of organic matter and the worst in reactor $13-44.46 \pm 0.14 \%$ and $45,83 \pm 0.58 \%$, respectively. Better depletion results were achieved after the implementation of the mesophilic fermentation.

The depletion efficiency of total carbon, inorganic carbon and TOC as a result of the mesophilic and thermophilic fermentation is presented in Figure 3. The depletion efficiency of carbon compounds is conditional upon the type of fermentation as well as the composition of
Table 1. Research methodology

\begin{tabular}{|l|l|}
\hline \multicolumn{1}{|c|}{ Parameter } & \multicolumn{1}{c|}{ Method/norm/equipment } \\
\hline Dry matter (dm) & Gravimetric method \\
\hline $\begin{array}{l}\text { Organic matter } \\
\text { (om) }\end{array}$ & Gravimetric method \\
\hline Total carbon & $\begin{array}{l}\text { High-temperature infrared } \\
\text { decomposition } \\
\text { Analytik Jena TOC multi NC 3100 }\end{array}$ \\
\hline Inorganic carbon & $\begin{array}{l}\text { High-temperature infrared } \\
\text { decomposition } \\
\text { Analytik Jena TOC multi NC 3100 }\end{array}$ \\
\hline $\begin{array}{l}\text { Total organic } \\
\text { carbon (toc) }\end{array}$ & $\begin{array}{l}\text { High-temperature infrared } \\
\text { decomposition } \\
\text { Analytik Jena TOC multi NC 3100 }\end{array}$ \\
\hline Protein & Conversion factor N x 6.25 \\
\hline Sugars & $\begin{array}{l}\text { Gas chromatography on GC/MS/MS } \\
\text { by Agilent Technologies 7890B }\end{array}$ \\
\hline $\begin{array}{l}\text { Fats (eter } \\
\text { extracts) }\end{array}$ & $\begin{array}{l}\text { Gravimetric method using solvent } \\
\text { according to the PN-86/C-04573/01 } \\
\text { norm }\end{array}$ \\
\hline
\end{tabular}

mixes subjected to this process. During the mesophilic fermentation, the depletion efficiency of total carbon and TOC was the highest in reactor $8(50 \%$ meat, $10 \%$ dairy, $40 \%$ fruit and vegetables) and amounted to: $87.28 \pm 0.62 \%$ and $86.30 \pm 0.53 \%$, respectively. The best effects of inorganic carbon depletion were obtained during fermentation in reactor 2 with the mix including: $10 \%$ meat, $50 \%$ dairy, $40 \%$ fruit and vegetables, amounting to: $98.02 \pm 0.10 \%$. The worst effects of total carbon and TOC depletion were achieved in reactor 13 (10\% meat, $40 \%$ dairy, $50 \%$ fruit and vegetables) $-77.73 \pm 0.35 \%$ and $75.24 \pm 0.65 \%$, respectively. Inorganic carbon was decreased with the lowest efficiency in reactor $9(50 \%$ meat, $10 \%$ dairy, $40 \%$ fruit and vegetables) $-95.73 \pm 0.31 \%$. On the other hand, in the case of thermophilic fermentation, the best effects of total carbon, TOC and inorganic carbon depletion were obtained during fermentation in reactor 8 . However, the values were lower, at the level of: $69.34 \pm 0.63 \%, 68.24 \pm 0.38 \%$ and $80.43 \pm 0.18 \%$, respectively. The worst depletion efficiency of carbon compounds were obtained in reactor 13 , amounting to $46.42 \pm 0.35 \%$ of total carbon, $46.04 \pm 0.48 \%$ of TOC and $49.23 \pm 1.37 \%$ of inorganic carbon.

The depletion efficiency of protein, sugars and fats as a result of the mesophilic and thermophilic fermentation is presented in Figure 4. This efficiency is conditional upon the type of fermentation, as well as the composition of mixes subjected to the process. After mesophilic fermentation, the highest depletion efficiency of protein and fats was in reactor 8 (mix with the composi- 


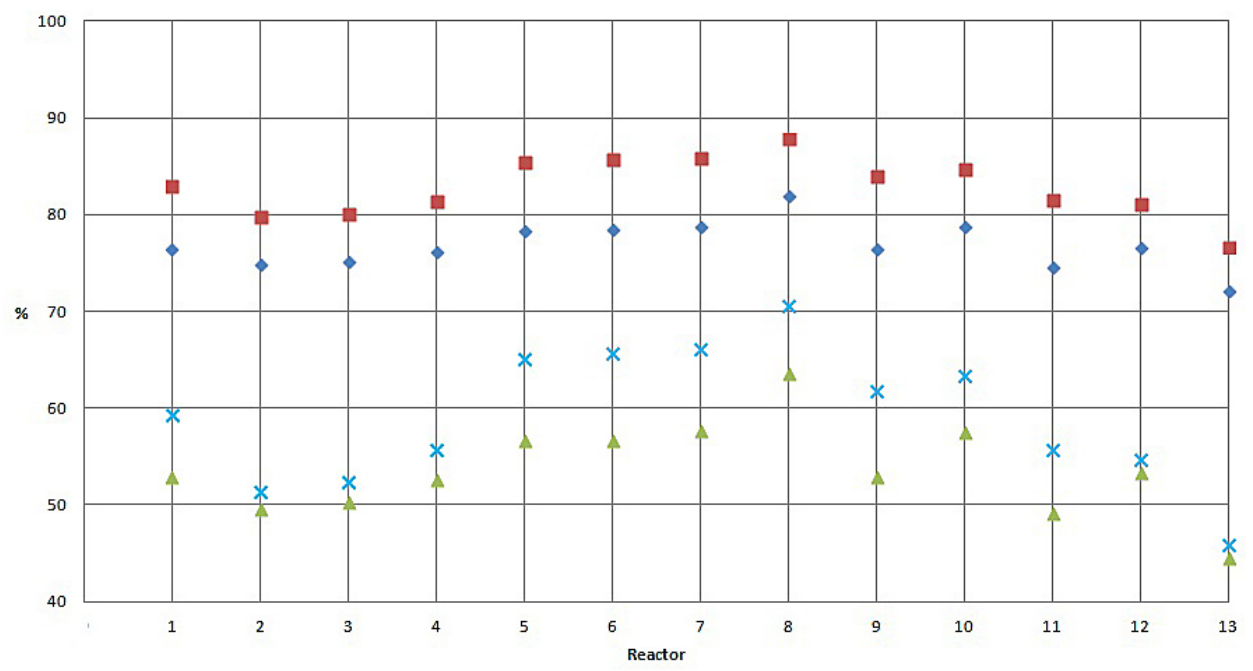

Fig. 2. Depletion efficiency in DM and OM as a result of the mesophilic and thermophilic fermentation

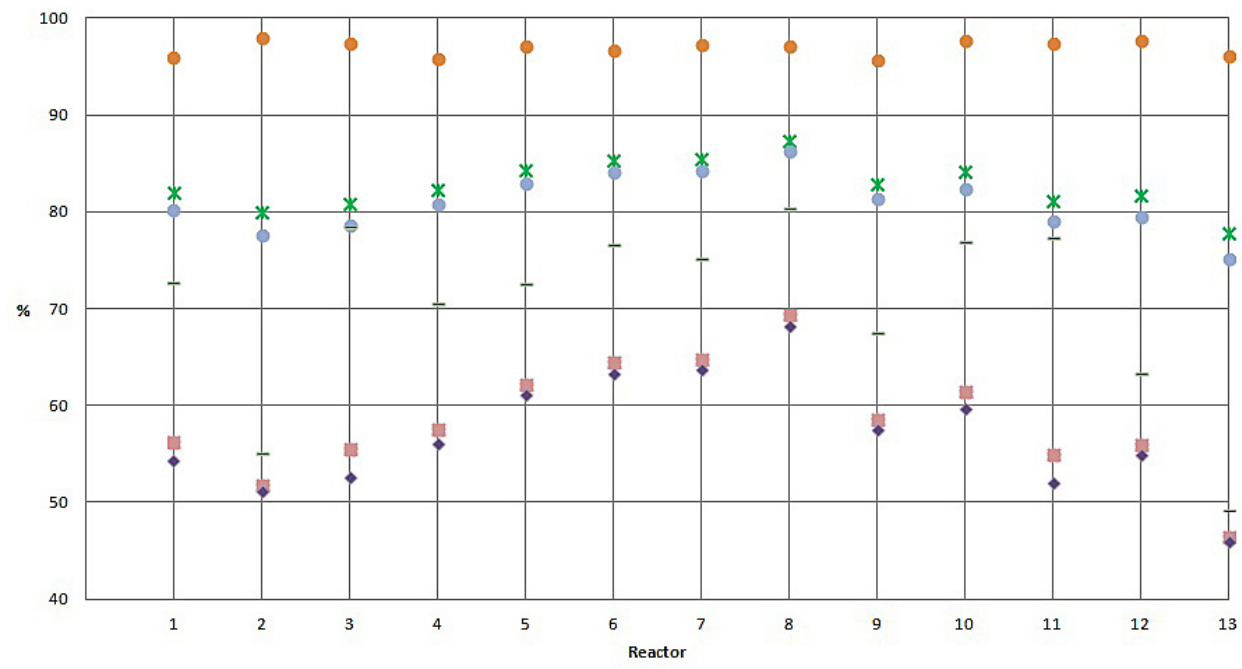

Fig. 3. Depletion efficiency of total, inorganic and total organic carbon as a result of mesophilic and thermophilic fermentation

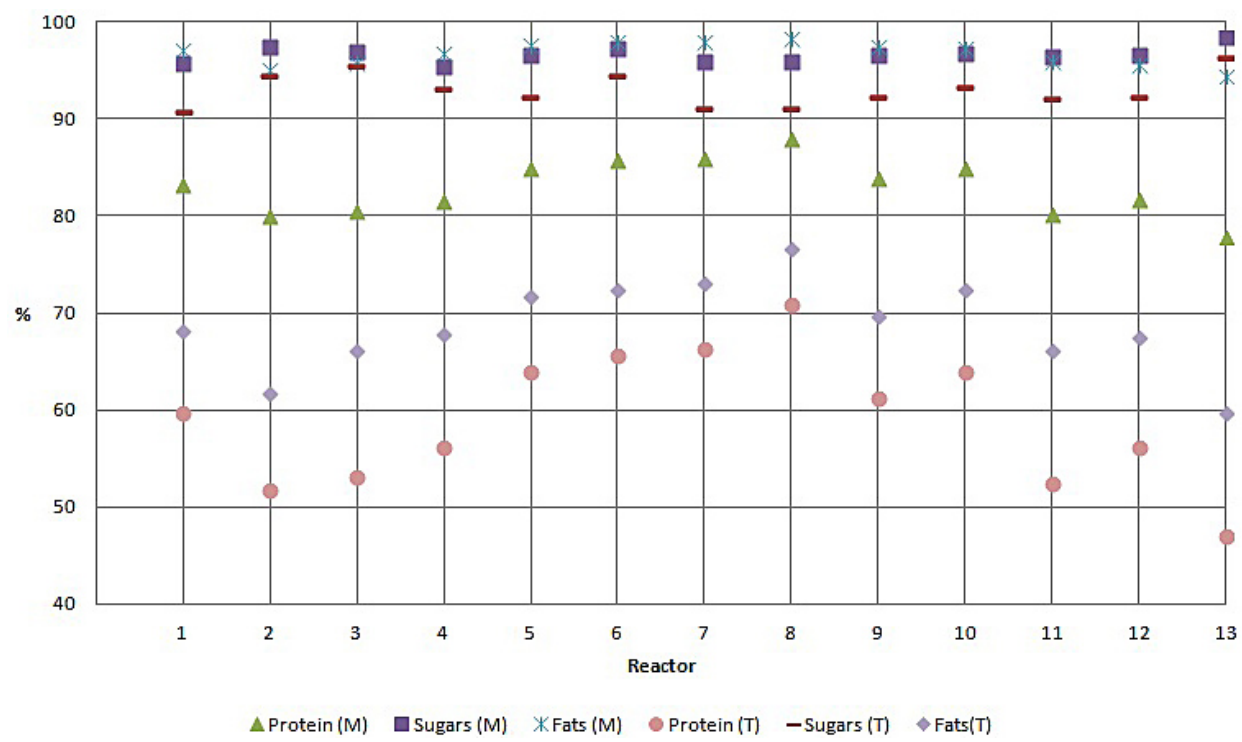

Fig. 4. Depletion efficiency of protein, sugars and fats as a result of mesophilic and thermophilic fermentation 
tion of 50\% meat, 10\% dairy, 40\% fruit and vegetables) $-87.95 \pm 0.30 \%$ and $98.35 \pm 0.07 \%$ and the lowest in reactor 13 (10\% meat, 40\% dairy, $50 \%$ fruit and vegetables), i.e. $77.92 \pm 1.27 \%$, $94.58 \pm 0.13 \%$. Very high depletion efficiency of sugars was achieved in all reactors, ranging from $95.39 \pm 0.003 \%$ in reactor $4(30 \%$ meat, $50 \%$ dairy, $20 \%$ fruit and vegetables) to $98.41 \pm 0.043 \% \mathrm{w}$ mix 13. The highest depletion efficiency of protein and fats after thermophilic fermentation was found in reactor 8 and it amounted to: $70.87 \pm 0.48 \%$ and $76.57 \pm 0.56 \%$, whereas the lowest in reactor 13 $47.04 \pm 3.03 \%$ and $59.68 \pm 1.14 \%$.

The thermophilic fermentation caused a content decrease of these components with lower efficiency than in the case of the mesophilic fermentation. However, the depletion efficiency of sugars was not much lower compared to the mesophilic fermentation and ranged from $90.83 \pm 0.226 \%$ in reactor 1 (equal share of expired food products in the mix) to $96.36 \pm 0.139 \%$ in reactor 13 .

The mesophilic conditions are practiced in the majority of Polish and foreign biogas plants, including the German ones (Sorda et al. 2013, Kuratorium für Technik und Bauwesen... 2011). Occasionally, elevated temperatures (thermophilic conditions) are used, which might accelerate biochemical reactions and increase the level of organic matter degradation to methane, but do not always result in the larger biogas production. According to Dinsdale et al. (1996) and Kabouris et al. (2009), they may bring unwanted effects in the form of lower process stability, raised sensitivity to inhibitors, as well as increased release of organic fatty acids. Additionally, implementing fermentation at elevated temperature is an energy-intensive process, which may be the reason to doubt its economic aspect as well as the profitability of methane production as a source of energy with the use of this method.

As Jędrczak (2008), Sung and Liu (2002) and Magrel (2004) claim, the process of methane fermentation proceeds as a result of decomposition of complex organic compounds, which in consequence leads to depletion of biomass organic matter subjected to fermentation. In the first stage of own research, the highest efficiency of organic matter removal was obtained during the mesophilic fermentation.

Jędrczak and Królik (2013) achieved a very high degree of meat offal decomposition in the process of the mesophilic fermentation. The values of index decomposition in the case of the thermophilic fermentation were 42 to $53 \%$ lower in comparison to the mesophilic fermentation.

The authors's own research confirmed the very high depletion effects of all parameters considered in the first stage of research, as a result of the mesophilic fermentation. The obtained efficiencies were ca. 20\% higher than the results achieved during the thermophilic fermentation. Sugars, where depletion efficiency was a bit higher, constituted an exception. The mix in reactor 8 (50\% meat, 10\% dairy, $40 \%$ fruit and vegetables), subjected to the mesophilic fermentation, was characterised by the best efficiency. Moreover, in reactor 6 (50\% meat, $40 \%$ dairy, $10 \%$ fruit and vegetables) as well as in reactor 7 (50\% meat, $30 \%$ dairy, 20\% fruit and vegetables) very high compounds depletion were achieved.

\section{CONCLUSIONS}

1. The depletion efficiency of the analysed components of substrates (dry matter, organic matter, carbon, protein and fat compounds) was over $20 \%$ higher owing to the application of the mesophilic fermentation than during the thermophilic fermentation. Only in the case of sugars, there were no significant differences arising from the type of fermentation used.

2. The composition of the used mixes of expired food products had a significant impact on the efficiency of the compounds depletion from substrates. The greatest depletion of these compounds was obtained during the fermentation of the mix consisting of 50\% meat, $10 \%$ dairy, $40 \%$ fruit and vegetables.

\section{Acknowledgements}

This article has been written within the work S/WBiIŚ/02/2014, funded by the Ministry of Science and Higher Education

\section{REFERENCES}

1. Dinsdale R.M., Hawkes F.R., Hawkes D.L. 1996. The mesophilic and thermophilic anaerobic digestion of coffee waste containing grounds. Water Research, 30(2), 371-377.

2. Głodek E. 2010. Guide. Biogas utilization. Institute of Ceramics and Building Materials, Opole.

3. Gradziuk P., Szmidt K. 1998. Technical, economic 
and ecological aspects of the use of biomass for energy purposes. Rearing of Bulk Plants, 2, 58-62.

4. Institute for Renewable Energy 2013. Biogas Production Use; http://www.ieo.pl/oferta/wydawnictwa/Biogaz\%20-\%20Produkcja\%20Wykorzystywanie.pdf

5. Jędrczak A. 2008. Biological waste treatment. PWN Publishing House, Warsaw.

6. Jędrczak A., Królik D. 2013. The impact of the degree of meat fineness on the efficiency of the fermentation process. University of Zielona Góra. Science Notebooks No. 152. Environmental Engineering, 32, 52-68.

7. Kabouris J.C., Tezel U., Pavlostathis S.G., Engelmann M., Dulaney J., Gilletle R. et al. 2009. Methane recovery from anaerobic co-digestion of municipal sludge and FOG. Bioresource Technology, 100, 3701-3705.

8. Kazimierowicz J., Dzienis L. 2015. Giant Miscanthus as a substrate for biogas production, Journal of Ecological Engineering, 16(4), 139-142.

9. Kazimierowicz J. 2014. Organic waste used in agricultural biogas plants. Journal of Ecological Engineering, 15(2), 88-92.

10. Kościk B., Kowalczyk-Juśko A. 2004. Cultivation and use of perennial plants for energy purposes. Pam. Col., 132, 203-210.

11. Kuratorium für Technik und Bauwesen in der Landwirtschaft: Biogas - production and use (BIOGAZ guide), Institut für Energetik und Umwelt gGmbH, Leipzig 2011.
12. Magrel L. 2004. Forecasting the methane fermentation process of a mixture of sewage sludge and slurry. Bialystok University of Technology Publisher, Bialystok.

13. Neterowicz J. et al. 2015. Energy from waste-Swedish experience and the Polish reality. PIMOT Scientific Publisher, Warsaw.

14. Pawilonis J., Kupczyk A. 2006. Biogas as a source of renewable energy in Poland - production potential, current status and development perspectives of the sector. „Fermentation and fruit and vegetable industry", 12.

15. Puyuelo B., Gea T., Sánchez A. 2010. A new control strategy for the composting process based on the oxygen uptake rate. Chemical Engineering Journal, 165, 161-169.

16. Sadecka Z. et al. 2013. Substrates for the co-fermentation process. Environmental Engineering Scientific Papers, 150, 23-33.

17. Sorda G., Sunak Y., Madler R. 2013. An agentbased spatial simulation to evaluate the promotion of electricity from agricultural biogas. Ecological Economics, 89, 43-60.

18. Sung S., Liu T. 2002. Ammonia inhibition on thermophilic aceticlastic methanogens. Water Sci. Technol., 10(45), 113-120.

19. Szatkowska B., Paulsrud B., Tonderski A. 2014. Assessment of biogas potential of organic waste in the Pomeranian Voivodship. IV Baltic Biogas Forum, Gdańsk, 11-12 September. 